\title{
Research on Marx's Income Distribution Theory: a Literature Review
}

\author{
Xing $\mathrm{He}$ \\ School of Economics \\ Intensive Language Training Center \\ College of International Studies \\ Sichuan University \\ Chengdu, China
}

\begin{abstract}
The issue of income distribution is an important part of Marxist political economy. In recent years, with the continuous emergence of problems in the field of income distribution in China, the research on Marx's income distribution theory has gradually increased. Based on the integration of data, this paper combs the overall status quo of the research on Marx's income distribution theory, reviews the main contents of Marx's income distribution theory, summarizes the comparison between Marx's income distribution theory and western economic distribution theory, expounds the sinicization process of Marx's income distribution theory, and puts forward the reflection on Marx's income distribution theory, which can reflect the current academic research on this issue, and provide reference for the further study of Marx's income distribution theory.
\end{abstract}

Keywords-income distribution theory; Marx; research summary

\section{INTRODUCTION}

Based on the theory of labor value, Marx's income distribution theory is an important part of political economy, which still has important theoretical and practical significance. In recent years, with various problems in the field of income distribution emerging from the beginning to the deepening of contradictions, academia and other social sectors have paid extensive attention to the problem of income distribution. How to recognize and deal with the new situation and problems in the field of distribution is the current problem, but also the focus of debate. At the same time, the research on Marx's income distribution theory is increasing and more detailed, including the combing of the formation process and main contents of the theory, the explanation and guidance of the theory to the reality, and the in-depth summary of the theoretical research and practical experience. In recent years, a lot of academic works and articles have been published. These documents use different methods to discuss this issue from different perspectives. This paper summarizes the four aspects of the theoretical research on Marx's income distribution theory, including the main content of Marx's income distribution theory, the comparison with the western mainstream distribution theory, the evolution of the theory in China, and the problems still existing in the research. On the basis of summing up and comparing the discussions of various scholars, this paper makes an analysis in order to deepen the understanding of Marx's income distribution theory and help to further explore the situation and problems of income distribution in theory and practice.

\section{MAIN CONTENTS OF MARX'S INCOME DISTRIBUTION THEORY}

Marx's theory of income distribution is developed on the basis of sublating the theory of income distribution in classical economics, and criticizing "Smith Doctrine" and Say's "Trinity formula". The theory is based on the theory of labor value, including wage theory, surplus value theory, interest and land rent theory. It is a complete theoretical system. In summary, the core content mainly includes the following aspects.

\section{A. Production Relationship Decides Distribution Relationship}

Distribution is an important aspect of Marx's study of production relations. Marx said that "the so-called distribution relationship is compatible with the special social forms stipulated in the history of the production process and the relationship between people and each other in the reproduction process of their lives, and is generated by these forms and relations. The historical nature of these distribution relations is the historical nature of production relations. Distribution relations only represent one aspect of production relations." [1] According to Marx, the structure of distribution depends on the structure of production. It is an important feature of Marx's distribution theory to study distribution from the perspective of production. At this point, scholars have generally reached a consensus.

According to the "Modern Analysis of Das Kapital" compiled by Hong Yinxing and others, "the distribution of means of production determines the position of social members in the process of production, at the same time, it also determines the nature and mode of distribution of social members among all kinds of production, as well as the distribution objects and the quantity of products available for distribution." [2] Since the factors of production are allocated in a certain way, the consumption materials should also be 
allocated in a corresponding way. In the capitalist economy, the capitalist controls the capital, but the laborer only has the personal production condition labor force. Workers can only get remuneration by their own labor, while capitalists get surplus value by their ownership of capital. Therefore, distribution is the product of production. The distribution of means of production or production conditions determines the distribution of income. He Hua pointed out in "Re-discussing Marx's Distribution Theory and Its Practical Significance Rereading the Critique of the Gotha Program" that "the distribution of production conditions mainly refers to the form of ownership of production materials, which is the social form that material production and person production combine. The combination determines the nature of production mode and the nature of the distribution." [3] Gu Yaguang and Dong Quanrui discuss in "Marx's Theory of Income Distribution and Its Contemporary Values": "Production relations must change with the change of production. The distribution of capitalism is different from the distribution methods produced by other modes of production, and each form of distribution will disappear with the certain form of production from which it arises and adapts to."[4]

\section{B. Source and Distribution of Income}

The seventh part of the third volume of "Das Kapital" examines the various incomes and their ultimate sources in capitalist society. Engels once said that the third volume of "Das Kapital" expounds the distribution law of surplus value. In "The scope and principle of Das Kapital - question and answer", Cheng Baoliang and others put forward when talking about Marx's income distribution theory: "it is divided into various specific forms precisely because of the surplus value and belongs to different exploitation groups. And then, all kinds of specific forms of capital exist, these exploitation groups survive and the whole capitalist organization operate normally." [5] The essence of distribution can be seen. The third volume of "Das Kapital" is the end of Marx's research on the theory of capitalist mode of production, which completes the demonstration of the theory of generalized surplus value, and constitutes a complete and rigorous scientific system.

First of all, the source of all kinds of income is the new value created by labor. Marx analyzed and criticized the "trinity" formula of Western classical economists, namely the theory of "capital-profit, land-land rent, labor-wage", and further studied the various incomes and sources of capitalist society. The source of all kinds of income such as wages, interest, corporate profits and land rent is the new value $\mathrm{V}+\mathrm{m}$, and the only source of value is labor. There is always value creation before value distribution. In fact, various incomes of capitalist society are transformed from the value created by the labor of hired workers. The new value created by the labor of the workers is distributed between labor and different exploiting groups, which reflects a certain distribution relationship. "Modern Analysis of Das Kapital" points out: "Marx believes that the fundamental error of the Trinity formula lies in its violation of the labor value theory, and denies that the source of value of all these forms of income is labor. Capital, labor and land are equally regarded as the source of value." "In Marx's view, the correct expression should be capital — interest; land ownership rent; employment labor - wage. In this way, the formula should include links among various sources of income." [2]

The distribution of surplus value is the core of capitalist distribution. The fundamental purpose of capitalist production is to produce surplus value, so the distribution of capitalism should also focus on the distribution of surplus value. This new value takes various forms of distribution and distribution relations. This is determined by the production form, that is, the relations of production. Therefore, the production relationship should be realized by the distribution relationship in turn. There are some researches on the adjustment of the relationship between Marx's income distribution theory and modern distribution in the "Research on Das Kapital and some hot issues of contemporary economic theory. It is pointed out that the key point of Marx's analysis on capitalist distribution relationship is the distribution of surplus value. Distribution includes two aspects: firstly, industrial capitalists get average profit through sector competition, that is, equal amount of capital gains equal amount of profit; secondly, loan capitalists and landowners get interest and land rent by virtue of ownership. [6] "Theory of income distribution and modern enlightenment" reveals that the production of surplus value is the direct purpose and decisive motive of capitalist production, and there will be serious contradictions in the distribution share of capital and labor. On the one hand, capitalist production reflects the relationship between employment and exploitation. On the other hand, it reflects the distribution relationship between capitalists and workers. [7]

\section{Distribution According to Work and Distribution According to Production Factors}

In "Das Kapital", Marx called the future society as the community of free individuals. In "Critique of Gotha Program", Marx distinguished two stages of communism, namely the first stage of communism and the advanced stage of socialist society and communism. In the first stage, due to the capitalist characteristics and traces, the principle of distribution according to work should be implemented. In the advanced stage of communism, labor is not only a means of making a living, but also can be distributed according to needs.

In "Modern Analysis of Das Kapital", Hong Yinxing makes a detailed explanation on the definition of labor according to the scale of labor distribution. He believes that the "labor" in the distribution according to work refers to the "social average labor time". The individual labor time of each laborer must be converted through the unified scale of social average labor time before it can be used as the scale of distribution of his personal consumer goods. People can't realize their own special interests by possessing better means of production, and the influence of this objective factor should be deducted in the distribution of personal consumer goods. He further proposes that the content of Marx's distribution according to work theory is as the following: the 
distribution system of individual consumer goods in socialist society. Labor is the only yardstick for the distribution of personal consumer goods. The distribution object according to work is not the whole of the total social products, but the rest of the consumed means of production and so on. Equal labor exchange is a relationship of equal proportion. This kind of relationship only exists among workers, but not between individuals and society. The relationship between individuals and society shows that individuals fulfill their production obligations to society, and society allocates equal remuneration to the proportion of workers and their labor in the total average labor of society according to the contribution of each person's labor. [2]

Distribution according to work is closely related to the current distribution practice, which accounts for a large proportion in the study of Marx's distribution theory. In the early days of the founding of the people's Republic of China, the Soviet scholar Li Yabin's "distribution according to work - socialist economic law" explained the nature of distribution according to work, the development of the system, the form of wages and so on, which had a good reference value for the study of distribution according to work. After the reform and opening up, most of the discussions on distribution according to work are included in the compilation of the minutes of the seminar on distribution according to work, with the focus on the scientific connotation of distribution according to work. At present, the discussion on distribution according to work is still in progress. These discussions are mainly focused on two aspects. One is the realization conditions and forms of distribution according to work; the other is the relationship between distribution according to factors and distribution according to work. As for the first point, Hu Liansheng points out in "The discussion on the formation, development and realization of Marx's distribution theory according to work" that, unlike Marx's early expectations, China has implemented the socialist market economy system and diversified interest subjects. The production factors belonging to different interest subjects, such as capital, land, real estate, labor, technology and information, play different and indispensable roles in the process of labor creating value. Therefore, various production factors need to be evaluated by the market. [8] Under such conditions, if it still distributes according to the factors of production, it will deviate from the essence of socialism. However, if it completely implements the distribution according to work, it will violate the law of market economy. Therefore, it is necessary to adhere to the distribution system with distribution according to work as the main body and multiple distribution modes coexisting. In "Rethinking on Marx's distribution theory", Zhang Yanxi points out that Marx's distribution according to work needs to meet many conditions: the public ownership of the means of production in the whole society, the disappearance of commodity exchange, the elimination of various confrontations in labor, and the "community of free individuals" of laborers. The current distribution according to work in China is the same in nature as the distribution according to work put forward by Marx, but there are differences in the personal or social nature of labor and the amount of labor. This difference makes the distribution according to work at this stage not direct, but indirect. [9] In addition, Chapter 8 of "Advanced political economy" is on the development of surplus value theory and its contemporary significance. Zhang $\mathrm{Yu}$ and others discuss that if distribution according to work is understood as a form of future social wealth distribution envisaged by Marx, this specific form can't be implemented in the market economy. The form of distribution according to work that Marx conceived on the basis of surplus value theory is based on the premise of complete public ownership and the disappearance of commodity economy. [10] On the second point, "The theory of socialist economy" edited by Yang Ruilong, points out that the coexistence of multiple ways of income distribution is determined by the distribution of production conditions at the present stage in China, which is an objective requirement for the development of the socialist market economy in China and an important feature of the income distribution system of the socialist market economy. First of all, the combination of distribution according to work and distribution according to production factors is the combination of labor standard and ownership standard of income distribution. Secondly, the combination of distribution according to work and distribution according to factors is the combination of the realization form of distribution according to work and distribution according to factors. In the socialist market economy, the combination of distribution according to work and distribution according to factors can make the income distribution modes in various ownership economy of China permeate, influence and supplement each other. [11] In addition, Huang Ping and Zhang Cungang hold similar views in "Theory of labor value, distribution according to work and distribution according to factors". [12]

It can be seen that as for distribution according to work or distribution according to factors, scholars mainly discuss from what distribution according to work is, the requirements of distribution according to work for socialist public ownership, the necessity of distribution according to factors and distribution according to work, and explain the rationality of the system of distribution according to work as the main mode and coexistence of various distribution modes under the current market economy in China.

\section{MARX'S INCOME DISTRIBUTION THEORY AND THE DISTRIBUTION THEORY OF WESTERN ECONOMICS}

An important perspective of the study on Marx's income distribution theory is to compare it with the western mainstream distribution theory. On the one hand, it is necessary to sort out the origin of the two distribution theories, on the other hand, it is necessary to compare the two distribution theories and identify their scientificity. In terms of theoretical origin, scholars generally believe that "Smith doctrine", Say's "Trinity" formula, Lasalle's distribution determinism and Marshall's "rare talent determines profit" represent the development of distribution theory in western mainstream economics. Zhao Xueqin's "Comparison between Marxist economics and western economics distribution theory and its reference" mainly introduces three representative figures of distribution theory 
according to productive factors. The idea of distribution according to productive factors can be traced back to Adam Smith. According to his point of view, in the capitalist society, the value of goods is finally distributed to three aspects, namely, to pay wages to the workers, to give profits to the capital owners and to give land rent to land owners. Smith Doctrine was developed into the "Trinity" formula by Say, who further proposed that the prices of the three factors were determined by the market supply and demand. This formula has long been respected by western economists. Later, Marshall, a representative of the neoclassical school, first regarded entrepreneurship as a factor of production on the basis of Trinity formula. Since then, it became the fourth factor of production in parallel with labor, capital and land. Marshall believes that, like other factors, the supply factor of entrepreneurial talent also depends on its production cost, and rare talent is an important factor in determining profits. In contrast, Marx advocates that production decides distribution. The starting point of his theory is to serve the proletariat. Also, it is the distribution theory under the condition of public ownership. His theory of value creation is the theory of labor value, which is divided into two parts: necessary labor value and surplus labor value. [13] In Marx's criticism of "Smith Doctrine" and its practical significance, Zhang Xian discusses Marx's criticism of the functional income distribution theory in neoclassical economics. Through theoretical analysis and empirical test, this paper proves that factor distribution theory is not the distribution law of market economy. On the contrary, the theory of factor distribution only mathematicizes and refines the "Smith Doctrine" under the marginal concept. Therefore, Marx's criticism of "Smith Doctrine" is also applicable to the theory of factor distribution. [14]

As for the comparison of the two theoretical systems, most scholars mainly analyze from the following aspects: the first is the analysis of the two theories. It is generally believed that the theory of distribution according to factors in western economics is based on the perspective of private ownership to understand the distribution issues, while Marx's distribution concept is based on the position of the proletariat. The second is institutional premise of the two theories. The premise of the distribution according to factors is the economic system of capitalist private ownership, and distribution according to work is based on the common possession of all factors by all members of society. In "The Comparative Analysis of Income Distribution Theory: Marx and Neoclassical", Feng Sujie compares two distribution theory systems from five aspects: research perspective, value theory basis, research method, research purpose and research focus. [15] Liu Wenchao also compares the methodology of the two systems in the "Comparison of income distribution theory between Marxist economics and Western Economics - Based on the perspective of critical realism". In order to distinguish the scientificity of the two systems, he adopts the perspective of structural ontology in critical realism to study the distribution theory in Marxist economics. He thinks that there are two levels in the field of income distribution that Marx understood: the surface phenomenon and the deep essential structure. The former includes the perceptible income distribution relations of economic subjects such as labor sale, law of supply and demand, wage form, property right protection and contract freedom, while the latter is the fundamental mode of production. Comparatively speaking, the income distribution theory of western economics adheres to the empirical ontology and believes that what can be perceived in the field of distribution is true. Although they have found the seemingly deep marginal productivity theory for their supply and demand distribution, it is only a synonymous repetition of the concept of market supply and demand. Because of this, it has more explanatory power to the practical problems, especially the changes of income distribution pattern of contemporary capitalism, and the rising labor cost in China. [16]

Concluding and summarizing the multi-angle analysis of Marx's distribution theory and the western mainstream distribution theory, it will be found that no matter what angle of view is adopted to analyze and demonstrate, the ultimate goal is to return to the problem of economic relations or market phenomenon. About the scientificity of the two theories, most scholars still hold that Marx's theory of income distribution is the real scientific theory, which should be used to guide China's income distribution policy and practice. However, scholars also affirm that many viewpoints in western distribution theory can be used for reference in the current development of socialist market. For example, Sun Haojin demonstrates the reference and development of the mainstream views of some representative figures of western distribution theory in "the development and abandonment of western income distribution theory - the enlightenment to China's income distribution reform". [17] In addition, Zhang Junshan's "thinking about some problems in the current research of income distribution theory in China" also comments on the research of the western income distribution theory on increasing income gap. He believes that western income distribution theory divides the research of income distribution into scale research and functional research. The former mainly analyzes the population size and proportion of each income level quantitatively, while the latter focuses on the income proportion and income level of each element. [18] Zhang Junshan also expresses similar views in "thinking about some problems in the current theoretical research of income distribution in China". The enlightenment of western distribution theory to the classification of research characteristics is to divide the research of distribution into income distribution research and income distribution process and basis research, which provides a new perspective.

\section{HistoricAl PROCESS OF SinicIZATION OF MARXIST DISTRIBUTION THEORY}

The process of sinicization of Marxist economics is the process of the combination of the basic theory of Marxist economics and Chinese practice and the continuous enrichment and development. Zhang Yu, Meng Jie and Lu Di pointed out in their book "advanced political economy": "Sinicization (of Marxist Economics) is the spatial form of Marxist economics innovation, while modernization is the temporal form of Marxist economics innovation. The innovation of Marxist economics is mainly embodied in the sinicization and contemporaneity of Marxist economics. 
Only by combining the two can the innovation of Marxist economics be realized. "[10] Therefore, many important theories in the theoretical system of socialist economy with Chinese characteristics, including the income distribution theory and the theory of fairness and efficiency, are also important issues in the study of contemporary Marxist economics. It is of great significance to promote the development of the basic theory of Marxist economics.

On the process of sinicization of Marxist income distribution theory, Yang Hui's "historical process and experience of sinicization of Marxist personal income distribution theory" is more representative. He divides this historical process into two major stages in the field of reform and opening up. Before the reform and opening up, there was a single stage of distribution according to work that emphasized "fairness", which was the first stage of combining Marx's theory of distribution according to work with China's reality. At this stage, people mainly followed the example of the Soviet Union and implemented a single distribution according to work. Because of the influence of the "left" thought, the principle of distribution according to work gradually evolved into the equalitarian "big pot rice" in practice, reducing the production efficiency. After the reform and opening up, China has experienced a new period of the development of distribution theory. The achievements of this period are embodied in Deng Xiaoping's income distribution theory. Such a period can be subdivided into the following stages: the first is the exploration period of sinicization of Marxist income distribution theory. From the Third Plenary Session of the 11th Central Committee of the Chinese Communist Party to the Third Plenary Session of the 14th Central Committee of the Chinese Communist Party, the "multiple" distribution stage emphasized the "efficiency". This period broke the egalitarianism and insisted on the principle of distribution according to work, but not the only one. Income differences were allowed. This period was in line with the changes of China's economic structure. The second is the period of vigorous development and adjustment of the sinicization of Marxist income distribution theory. Since the the Third Plenary Session of the 14th Central Committee of the Chinese Communist Party, it has been a distribution stage with both "efficiency" and "fairness". The the Third Plenary Session of the 14th Central Committee of the Chinese Communist Party proposed that individual income distribution should adhere to the system of distribution according to work as the main body and multiple distribution modes coexisting. For the first time, the principle of "efficiency first and fairness considered" was put forward. In the report of the 15th National Congress of the Communist Party of China, it proposed to combine distribution according to work with distribution according to production factors, and the income system had been promoted from "coexistence theory" to "combination theory", recognizing the combination and compatibility of distribution according to work and distribution according to factors. The 16th National Congress of the Communist Party of China first proposed the principle of "the production factors such as labor, capital, technology and management participating in the distribution according to their contributions", marking the maturity of China's income distribution system. At the 17th National Congress of the Communist Party of China, it proposed that the relationship between efficiency and fairness should be well handled in both primary distribution and redistribution. Redistribution should pay more attention to fairness. Income distribution should highlight the fundamental interests of the people. It is necessary to break through the principle of "efficiency first, fairness considered" and put efficiency and fairness on the same important position. [19]

In "analysis on the development process of Marxist theory of distributive justice in China", Liu Danping and Chen Zixuan have a new way to analyze the development of Marxist theory of income distribution in China from the perspective of distributive justice and fairness. According to the time node, this paper also divides the development stages of Marx's distribution theory in China. The difference is that it pays more attention to Marx's theory of distribution justice and the development of fairness and justice distribution policy in China, and the interpretation of the policy is different. For example, the article mainly discusses that after the reform and opening up, it is necessary to pay attention to the principle of fair competition and the principle of equal distribution on the basis of promoting the principle of distribution according to work. The report of the 13th National Congress of the Communist Party of China put forward that it is necessary to take common prosperity as the goal. On the other hand, it is possible to "prevent the gap between the rich and the poor", take effective measures to regulate the excessive personal income, and "reflect social equity on the premise of promoting efficiency." The Fifth Plenary Session of the Fourteenth Central Committee points out that from the ninth five-year plan, it should implement policies that are conducive to alleviating the trend of widening the gap, especially to take measures to solve the problem of too large social distribution gap, so as to protect the rights and interests of vulnerable groups in the labor market. The 15th National Congress of the Communist Party of China proposed a number of policies to promote fairness and justice, including "banning illegal income, rectifying unreasonable income, regulating income distribution", and regulating excessive income through improving the tax system to prevent two-level differentiation. The report of the 16th National Congress of the Communist Party of China put forward that the first distribution should focus on efficiency and the fairness of distribution rules; the second distribution should focus on fairness and narrow the income gap through government intervention. [20]

As for the historical process of the sinicization of Marx's income distribution theory, the theoretical circle tries to define and induce from each perspective, and the scholars have their own elaboration. However, it should be noted that there is its own law of development in the process of sinicization of Marx's income distribution theory, which can find some clues from the practice of Marx's economic theory and China's reform and opening up. As a part of the theory of political economy, the development and innovation of Marxist income distribution theory in China is similar to the evolution of economic theory and practice. Therefore, in the combing process, Jiang Yongmu's "basic characteristics of 
Marxist economics in China" and Wang Fang's "review of the sinicization of Marxist economics" can provide a good reference.

\section{CONCLUSION}

Distribution plays an important role in human social and economic life. Distribution is related to the vital interests of each social member, and has an important impact on social reproduction and economic growth. The reform of the income distribution system needs to address the practical interests that the people are most concerned about, and is also an important way to improve the people's material and cultural living standards. China has made great progress in theory and practice in the field of distribution after the reform and opening up, especially in recent years. However, the contradiction in the field of distribution is more prominent. At present, the main problems include: the low income of workers in the field of production and the distribution proportion of national income among the government, enterprises and residents. There are some unreasonable phenomena in the income distribution. The theoretical circle has analyzed them by using Marx's income distribution theory, western economic distribution theory and popular theory, and achieved some results.

However, it should be noted that some research results guided by Marx's distribution theory are just a rote copy of Marx's economic theory and lack the accurate analysis and grasp of the theory. In the name of Marx's distribution theory, some even use related concepts and terms to analyze the unreasonable phenomena in distribution practice superficially or even wrongly. For example, in the analysis of Marx's income distribution theory, the metropolis mentioned that the basis of the distribution theory is labor value theory, which recognizes that value is created by labor, and the income of the distribution object comes from labor. However, this is only the textbook definition, and has not become a theoretical tool to analyze practical problems. For example, whether there is exploitation in distribution according to production factors and how to promote the reform of income distribution also have the same problems. In addition, there are some theoretical and methodological defects in some documents which use Marx's income distribution theory as a guide to study the distribution problems in reality, making vulgar and popular theories and methods mixed in. For example, when explaining the "work" in the principle of "distribution according to work", it can't logically clarify its deep connotation, simply replace it with labor or contribution, and modify Marx's theory through dogmatism. In the discussion of "fairness and efficiency", if people don't distinguish the position and function of economic foundation and superstructure in social economy and the relationship between them and income, and generally use fairness and efficiency to discuss and explain the basis of income distribution, it is difficult to accurately reveal the factors that really affect income distribution. In fact, in the face of the current complex income distribution problem, if people don't have a deep understanding of the essence of Marx's distribution theory, excavate its rich connotation and innovate the theory, it can't provide a powerful weapon for the understanding and solution of the real problems.

Without a breakthrough in theory, it is difficult for practice to move forward. Therefore, only by using scientific abstract methods, grasping the basic content of Marx's distribution theory and organically linking the abstract theory with the real income problem can it promote the improvement and innovation of Marx's income distribution theory and provide accurate and rigorous theoretical tools for understanding and interpreting the real distribution problem.

\section{REFERENCES}

[1] Marx. Das Kapital, Volume III [M]. Beijing: People's Publishing House, 1975: 998-999. (in Chinese)

[2] Hong Yinxing et al. Modern Analysis of Das Kapital [M]. Beijing: Economic Science Press, 2005: 394-412, 418-420, 451-452. (in Chinese)

[3] He Hua. On Marx's Theory of Distribution and Its Practical Significance - Rereading the Critique of the Gotha Program [J]. East China Economic Management, 2011(4):123-126. (in Chinese)

[4] Gu Yaguang, Dong Quanrui. Marx's Theory of Income Distribution and Its Contemporary Value [J]. Journal of Management, 2011(10): 25-30. (in Chinese)

[5] Cheng Baoliang, Yang Zhi, Qiu Haiping. The Category and Principle of Das Kapital - Question [M]. Beijing: Economic Science Press, 2000: 326-328. (in Chinese)

[6] Liu Chao. Study on "Das Kapital" and some hot issues in contemporary economic theory $[\mathrm{M}]$. Beijing: China Social Sciences Press, 2009: 99-104. (in Chinese)

[7] Qiao Zhen, Xu Long. Marx's Theory of Income Distribution and Modern Enlightenment [J]. Journal of Hebei University of Economics and Business, 2014(3): 8-12. (in Chinese)

[8] Hu Liansheng. On the Formation, Development and Realization of Marx's Theory of Distribution According to Work [J]. Theoretical Discussion, 2013(5): 10-14. (in Chinese)

[9] Zhang Yanxi. Rethinking on Marx's Theory of Distribution [J]. Science Socialism, 2006(8):31-33. (in Chinese)

[10] Zhang Yu, Meng Jie, Lu Di. Senior Political Economics [M]. Beijing: Renmin University of China Press, 2006: 12. (in Chinese)

[11] Yang Ruilong. Socialist Economic Theory [M]. Beijing: Renmin University of China Press, 2008: 172-178. (in Chinese)

[12] Huang Ping, Zhang Cungang. Labor Theory of Value, Distribution According to Work and Distribution According to Factors [J]. Economic Review, 2002(1): 33-48. (in Chinese)

[13] Zhao Xueqin, Tan Liyang, Zhang Jiansen. Comparison and Reference of Marxist Economics and Western Economic Distribution Theory [J] Academic Monthly, 2000(11): 66-70. (in Chinese)

[14] Zhang Xian. Marx's Criticism on "Smith Doctrine" and Its Practical Significance [J]. Teaching and Research, 2004(2): 12-19. (in Chinese)

[15] Feng Sujie. Comparative Analysis of Income Distribution Theory: Marx and Neoclassical [J]. Economics Research, 2009(2): 24-27. (in Chinese)

[16] Liu Wenchao. Comparison of Marx's Economics and Western Economics' Income Distribution Theory - Based on the Perspective of Critical Realism [J]. Economic Problems Exploration, 2015(10): 165-170. (in Chinese)

[17] Sun Haojin. The Sublation of Western Income Distribution Theory On the Enlightenment of China's Income Distribution Reform [J]. Academic Exchange, 2008(10): 47-51. (in Chinese)

[18] Zhang Junshan. Reflections on Several Issues in the Study of Current Income Distribution Theory in China [J]. Economist, 2012(12): 21-2. (in Chinese) 
[19] Yang Hui. The Historical Process and Experience Enlightenment of Marxist Personal Income Distribution Theory in China [J]. Theoretical Journal, 2009(12): 63-66. (in Chinese)

[20] Liu Danping, Chen Zixuan. An Analysis of the Development Process of Marx's Theory of Distributive Justice in China [J]. Heilongiiang Social Sciences, 2010(4): 35-38. (in Chinese)

[21] Zhu Chunyan. Comparison of Western Mainstream Income Distribution Theory and Marx's Theory of Income Distribution [J]. Shandong Social Sciences, 2005(2): 120-122. (in Chinese) 